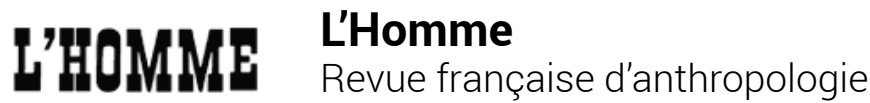

Jacques Dupâquier, ed., L'Espérance de vie sans incapacité. Faits et tendances, premières tentatives d'explication

Paris, PUF, 1997, X + 286 p. (« Sociologies »)

\section{Anne-Marie Peatrik}

\section{(2) OpenEdition}

\section{Journals}

Édition électronique

URL : http://journals.openedition.org//homme/248

DOI : 10.4000//homme.248

ISSN : 1953-8103

Éditeur

Éditions de l'EHESS

Édition imprimée

Date de publication : 1 décembre 2003

Pagination : 319-320

ISSN : 0439-4216

Référence électronique

Anne-Marie Peatrik, « Jacques Dupâquier, ed., L'Espérance de vie sans incapacité. Faits et tendances, premières tentatives d'explication », L'Homme [En ligne], 167-168 | 2003, mis en ligne le 11 septembre 2008, consulté le 22 septembre 2020. URL : http://journals.openedition.org//homme/248 ; DOI : https://doi.org/10.4000//homme.248

Ce document a été généré automatiquement le 22 septembre 2020.

(c) École des hautes études en sciences sociales 


\title{
Jacques Dupâquier, ed., L'Espérance de vie sans incapacité. Faits et tendances, premières tentatives d'explication
}

\author{
Paris, PUF, 1997, X +286 p. (« Sociologies »)
}

\section{Anne-Marie Peatrik}

1 AU COMMENCEMENT était la démographie. Fruit d'un colloque organisé à Paris en décembre 1995, l'ouvrage, publié sous la direction de Jacques Dupâquier, aborde la question du vieillissement démographique des populations par le truchement d'un concept qui donne son titre à l'ouvrage.

2 Derrière la technicité d'un intitulé qui peut dérouter le lecteur, se cache un mouvement de longue durée propre à nos sociétés dont Dupâquier (pp.1-4, 77-92) rappelle les grandes lignes. Au cours des deux derniers siècles, la tendance à l'augmentation de l'espérance de vie a été ininterrompue; de 1820 à aujourd'hui (en 1992) la durée moyenne de la vie a doublé (de 38,8 ans à 77,8 ans), tendance de fond qui résulte de plusieurs évolutions. À un gain continu de l'espérance de vie à la naissance qui s'explique par le recul séculaire de la mortalité infantile s'ajoute, depuis les trente dernières années, un recul de la mortalité du troisième âge (60-74 ans, «les jeunes vieux») et du quatrième âge ( 75 ans et plus, "les vieux vieux» ou le grand âge). L'amélioration de l'état de santé des populations s'explique par le reflux des maladies infectieuses et, plus récemment, des maladies cardiovasculaires et de certains cancers; le risque de tomber malade se trouve dissocié en partie du risque de mourir. L'augmentation continue de l'espérance de vie se surimpose, dans les pays développés, à la baisse de la fécondité amorcée en 1965, date à laquelle cesse la phase de baby-boom caractéristique des décennies qui ont suivi la Seconde Guerre mondiale. Ces différents mouvements se traduisent par un "vieillissement démographique des populations ", c'est-à-dire une modification de la structure par âge des effectifs à cause de l'augmentation, en nombre relatif et absolu, des individus âgés de 60 ans et plus, 
augmentation dont on constate actuellement les premières manifestations mais qui s'amplifiera dans les décennies à venir lorsque les baby-boomers deviendront à leur tour des anciens. Les tenants et les aboutissants de ce changement que les auteurs qualifient de "nouvelle aventure démographique», de "changement de régime démographique", ou encore "de révolution démographique " nécessiteront des recherches approfondies dans les domaines les plus divers, allant de la question de la longévité potentielle de l'espèce humaine à celle de la longévité différentielle selon les catégories sociales et à celle des inégalités sociales face à la mort, en passant par le contenu des politiques publiques puisqu'elles conditionnent les mesures à prendre qui anticipent ou accompagnent les changements. Le débat sur le régime des retraites peine à progresser et celui sur le système de santé est tout juste amorcé. C'est à ce dernier problème que s'attelle l'ouvrage en se focalisant sur ce que recouvre l'augmentation de l'espérance de vie du point de vue de la santé et de la maladie.

Étant donné que la probabilité de décéder à certains âges a diminué, de quoi sera faite la tranche de vie ainsi gagnée, et dans quel état allons-nous mourir ? Sachant que ces années gagnées sont sans précédent, en tout cas mesurable, dans l'histoire de l'humanité, quels concepts et quels outils permettront de connaître l'évolution de l'état de santé des populations "vieillissantes", d'apprécier les besoins et de prévoir les investissements et les dépenses de santé publique dans les décennies à venir? Divers scénarios existent (Jean-Marie Robine, pp. 7-31), selon que l'on table, ou non, sur l'expansion de la morbidité et sur l'existence d'un mur biologique infranchissable: les maladies qui ne se révéleraient qu'à un âge avancé auraient tendance, ou non, à augmenter. C'est à ces interrogations importantes que cherche à répondre le concept d'« espérance de vie sans incapacité » (EVSI), encore appelé "espérance de santé ». Comme tout indicateur, l'EVSI soulève des problèmes d'ordre statistique, mais aussi d'ordre idéologique, puisque tout outil d'évaluation, outre ses propres limites, est porteur, implicitement ou explicitement, de représentations et de jugements de valeur qui peuvent biaiser ou gauchir son utilisation et son utilité. Fruit d'une réflexion collective entre démographes, épidémiologistes, sociologues, économistes, psychologues, gériatres, l'ouvrage, composé de dix-sept communications suivies de discussions, s'articule autour de ces deux ordres de préoccupation.

\section{AUTEUR}

\section{ANNE-MARIE PEATRIK}

CNRS, Université Paris-X, Laboratoire d'ethnologie et de sociologie comparative, Nanterre. 